http://www.jfas.info

\title{
STUDY AND DESIGN OF U-SHAPED PATCH ANTENNA FOR MULTIBAND APPLICATIONS
}

\author{
M. N. Husin, M. T. Jusoh* and M. F. M. Din
}

Department of Electrical and Electronic Engineering, Faculty of Engineering, National Defence University of Malaysia, SungaiBesi Camp, Kuala Lumpur, Malaysia

Published online: 10 September 2017

\begin{abstract}
Recent mobile technologies require slimmer mobile phones to furnish several frequency bands with minimal number of installed antenna. Therefore, in this paper, U-shaped patch antenna for multiband is proposed, designed and analyzed. Despite using more than one antenna, only one antenna is sufficient to resonate at several frequencies. The proposed antenna resonates at three different frequencies which are $2.9 \mathrm{GHz}, 3.8 \mathrm{GHz}$ and $4.8 \mathrm{GHz}$ with optimum gains of $1.36 \mathrm{dBi}, 1.23 \mathrm{dBi}$ and $0.98 \mathrm{dBi}$ respectively. The antenna was designed and simulated using in CST software.
\end{abstract}

Keywords: U-shape antenna; multiband antenna; microstrip patch antenna.

Author Correspondence, e-mail: taufik@upnm.edu.my

doi: http://dx.doi.org/10.4314/jfas.v9i3s.45

\section{INTRODUCTION}

Nowadays, antenna has known as one of the most important elements in wireless communication system. It is use as radiating and receiving element in wide range of microwaves system such as radar, remote sensing, communication and radio frequency. By the early 21 st century, the evolution of antenna became rapid as the average person now 
carries one or more antenna on them wherever they go. By definition, an antenna or aerial can be described as an electrical device which converts electromagnetic photon into circuit current or vice versa [1]. The antenna can be either transmitting antenna or receiving antenna or both. In transmission, the antenna radiates the energy from the current as electromagnetic waves. While in reception, an antenna intercepts some of the power of an electromagnetic wave and converts it to electric signal. Fig. 1 shows basic antenna radiation.

There are many types, shapes and sizes of the antenna that available in the market. Example of some common types of antenna are dipole, loop, slot, patch, helical, horn and reflector.

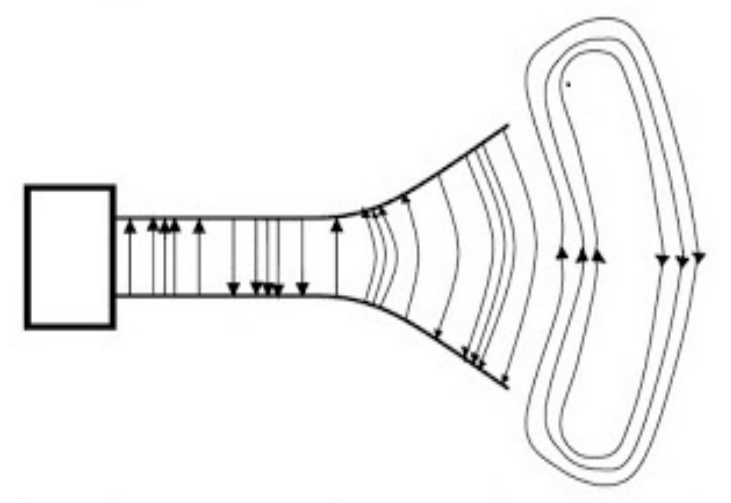

Fig.1. Basic antenna radiation

A microstrip [19] or patch antennas is a planar antenna, typically printed and have shaped of circular or rectangular, located above a ground plane and parallel to it [1]. It is known as patch antenna because the antenna had been patched on one side of dielectric substrate as shown in Fig. 2. The patch act as radiated antenna and has a ground plane to the other side of dielectric substrate. Cooper, gold and aluminum are some conducting materials that used as the patch. Patch antenna are widely used in many application due to their low profile, low cost and ease of fabrication over other antenna. In the other hand, the disadvantages of patch antenna are its low gain and narrow bandwidth [2]. The patch antenna radiate because of the fringing fields between the patch edge and the ground. 


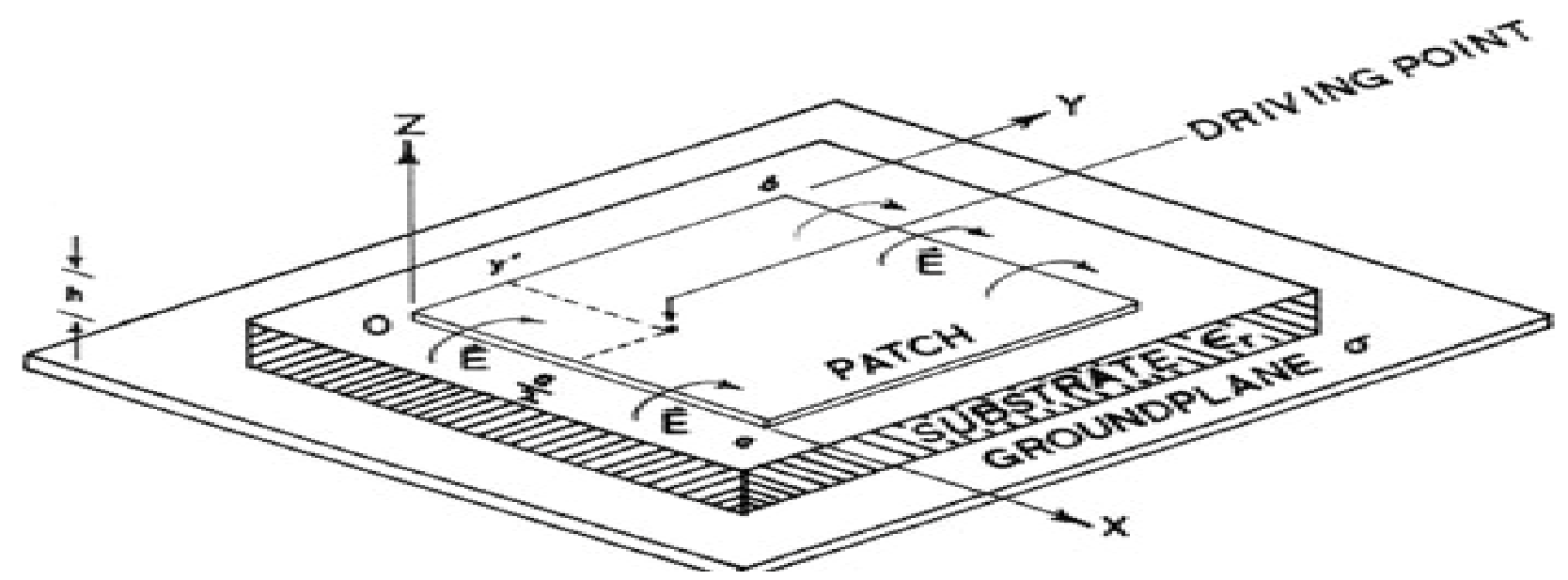

Fig.2. Basic structure of microstrip patch antenna $[3,20]$

In this research work, U-shaped patch antenna for multiband is designed and expected to operate at more than one frequency. The idea of U-shaped antenna was introduced by [4] in 1995. It was found that this U-shaped antenna ensures good radiation efficiency and larger impedance bandwidth of the antenna. However, the disadvantage of this U-shaped patch antenna is their narrow bandwidth and low gain [5]. Because of this, many ideas have been realized to overcome this problem. There are many applications in wireless communications that need more than one band of frequencies, and it becomes more crucial for military applications especially to facade their communication links.

Due to their characteristic and advantage, microstrip [21] patch antenna can be developed to meet dual and multiband frequency specification [7]. The advantage of having these multiband frequencies is it focuses only on the frequency of interest and thus make it more efficient [6], particularly in terms of lowering its profile.

\section{METHODOLOGY}

Basically, this project is divided into two main parts. The first part consists of the designing phase and the second part is simulating phase. Fig. 3 shows the geometry of the preliminary work in designing the U-shaped patch antenna. In this paper, the U-shaped patch antenna was designed for multiband application. First, all the important parameters are calculated using standard patch relationship and then followed by the design process. The standard formulas to calculate width and length of the patch antenna operate at multiband frequency are given as follows. 

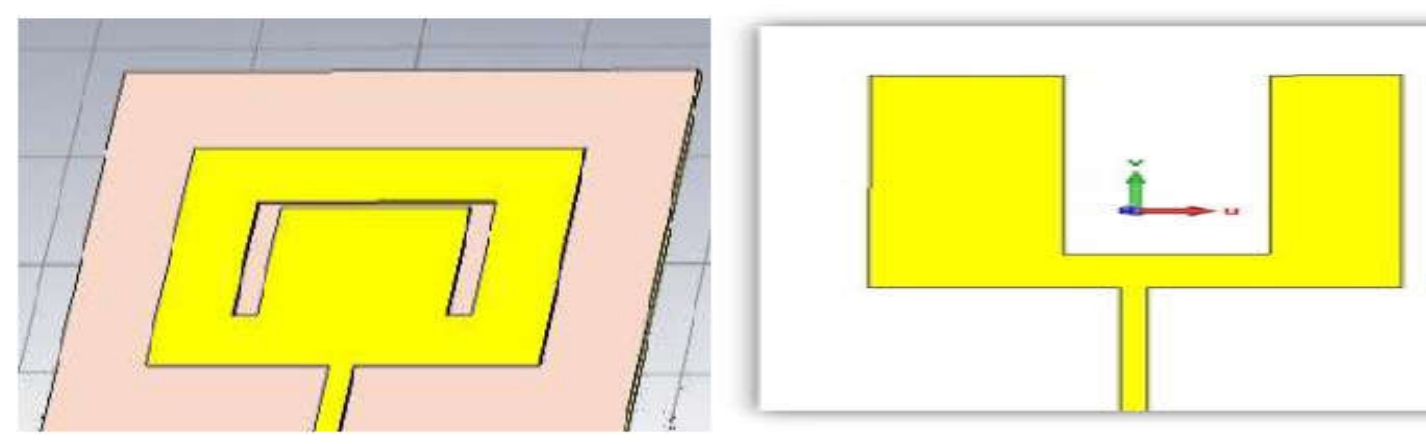

Fig.3.Simple U-shaped patch antenna [5]

$h=0.06 \frac{\lambda}{\sqrt{\varepsilon_{r}}}$

$W=\frac{v_{o}}{2 f_{0}} \sqrt{\frac{2}{\varepsilon_{r}+1}}$

$\varepsilon_{e f}=\frac{\varepsilon_{r}+1}{2}+\frac{\varepsilon_{r}-1}{2}\left[\frac{1}{\sqrt{1+12 \frac{h}{W}}}\right]$

$\Delta L=h \times 0.421\left[\frac{\left(\varepsilon_{e f}+0.3\right)\left(\frac{w}{h}+0.264\right)}{\left(\varepsilon_{e f}-0.258\right)\left(\frac{w}{h}+0.8\right)}\right]$

$L=\frac{V_{o}}{2 f_{r} \sqrt{\varepsilon_{e f}}}-2 \Delta L$

where $\mathrm{v}_{\mathrm{o}}=$ Speed of light, $\varepsilon_{\mathrm{ef}}=$ Effective dielectric constant, $\varepsilon_{\mathrm{r}}=$ Dielectric constant of substrate, $\mathrm{f}_{\mathrm{r}}=$ Fringing frequency, $\mathrm{H}=$ Height of dielectric substrate, $\mathrm{W}=$ Width of the patch and $\Delta \mathrm{L}=$ Extension of the length.After conducting some calculation, the parameters of the antenna are tabulated as shown in Table 1.

Table 1.Specifications of the proposed patch antenna

\begin{tabular}{cc}
\hline Parameters & Value \\
\hline Frequency $\left(f_{o}\right)$ & $2.45 \mathrm{GHz}$ \\
Patch Length $(l)$ & $30 \mathrm{~mm}$ \\
Patch Width $(w)$ & $38 \mathrm{~mm}$ \\
Dielectric constant $\left(\varepsilon_{r}\right)$ & 4.7 \\
Substrate Thickness $(h)$ & $2.4 \mathrm{~mm}$ \\
Substrate material & FR4 \\
Patch Material & Copper \\
\hline
\end{tabular}


The proposed antenna consists of a ground plane, FR4 substrate material, U-shaped patch and microstrip[22] feeding line as shown in Fig. 4. The patch and the ground are copper as shown inTable 1.

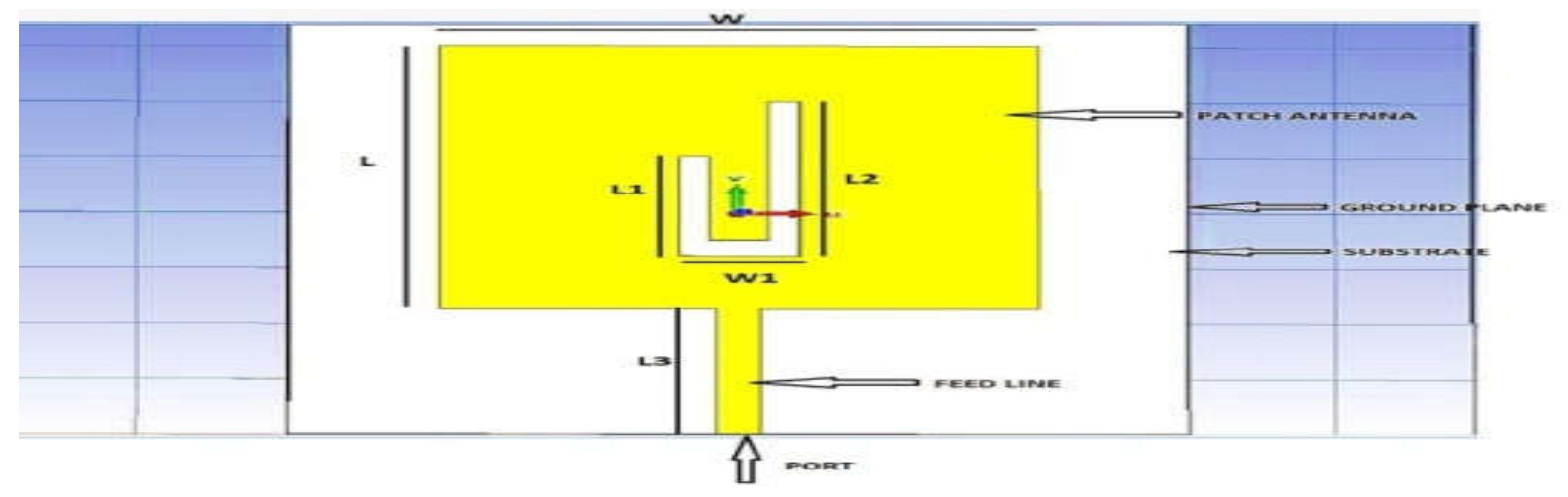

Fig.4. Geometry of proposed U-shaped patch antenna

Table 2 is the detailed dimensions of the proposed patch antenna designed. In this project, the parametric values of the antenna which is L1 have been manipulated and optimized to improve the performance of the antenna. The L1 is the variable while doing the calculation and the simulation. All the measurement is done in millimetre ( $\mathrm{mm})$. Table 3 shows the final dimensions of the proposed patch antenna designed.

Table

\begin{tabular}{cccccc}
\hline No. & $\mathbf{L 1}(\mathbf{m m})$ & $\mathbf{L 2}(\mathbf{m m})$ & $\mathbf{L 3}(\mathbf{m m})$ & $\mathbf{W} \mathbf{1}(\mathbf{m m})$ & $\mathbf{W} \mathbf{2}(\mathbf{m m})$ \\
\hline 1 & 28 & 28 & 24 & 8 & 3 \\
2 & 26 & 28 & 24 & 8 & 3 \\
3 & 24 & 28 & 24 & 8 & 3 \\
4 & 22 & 28 & 24 & 6 & 3 \\
5 & 18 & 28 & 24 & 8 & 3 \\
\hline
\end{tabular}

2.

Optimized 11, length of antenna 
Table 3.Dimension of U-shaped patch antenna

\begin{tabular}{cc}
\hline Parameters & Value $(\mathbf{m m})$ \\
\hline Patch length $(L)$ & 48 \\
Patch width $(W)$ & 40 \\
W1 & 8 \\
L1 & 18 \\
L2 & 28 \\
\hline
\end{tabular}

After the designing phase is completed, the calculated and measured data are simulated. Computer Simulation Tool (CST) Microwave Studio software are used to design and simulate the antenna.

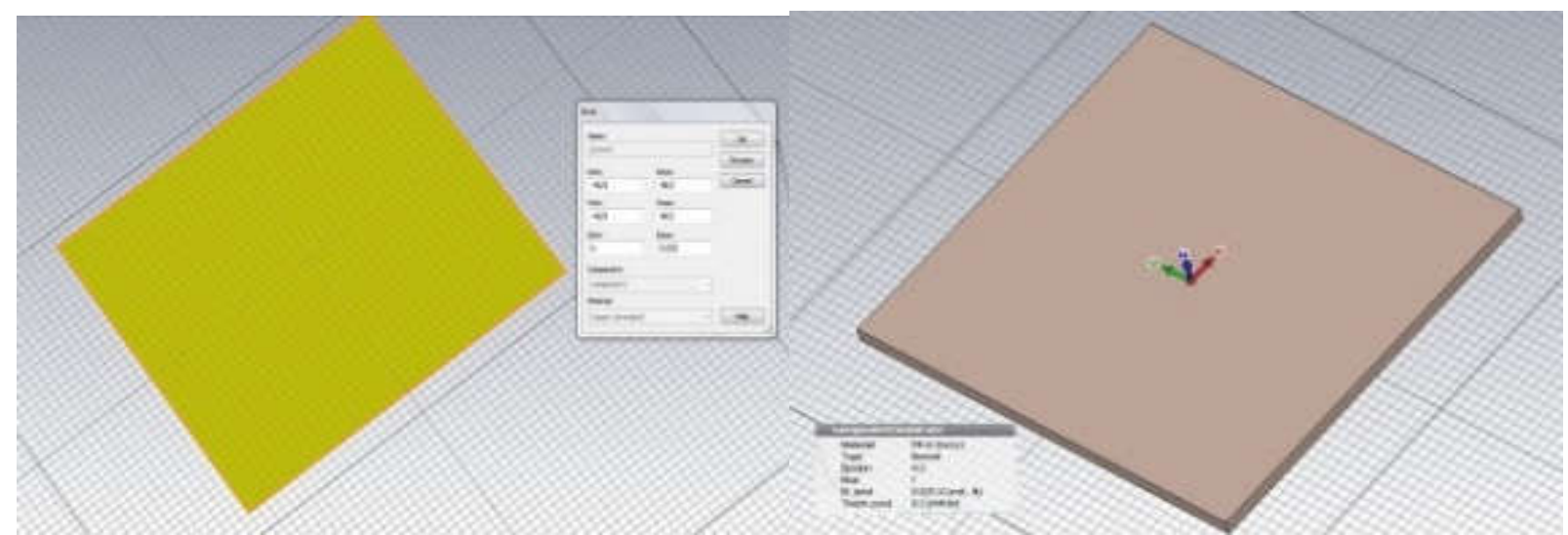

(a)

(b)

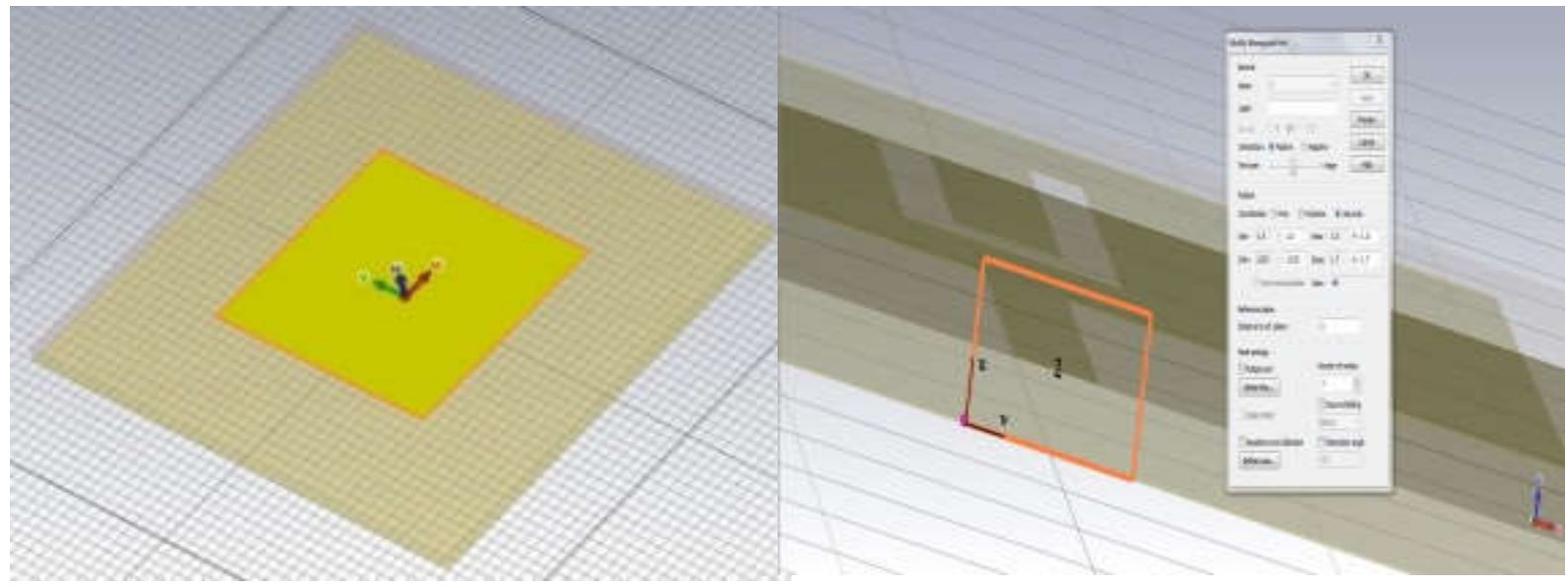

(c)

(d) 


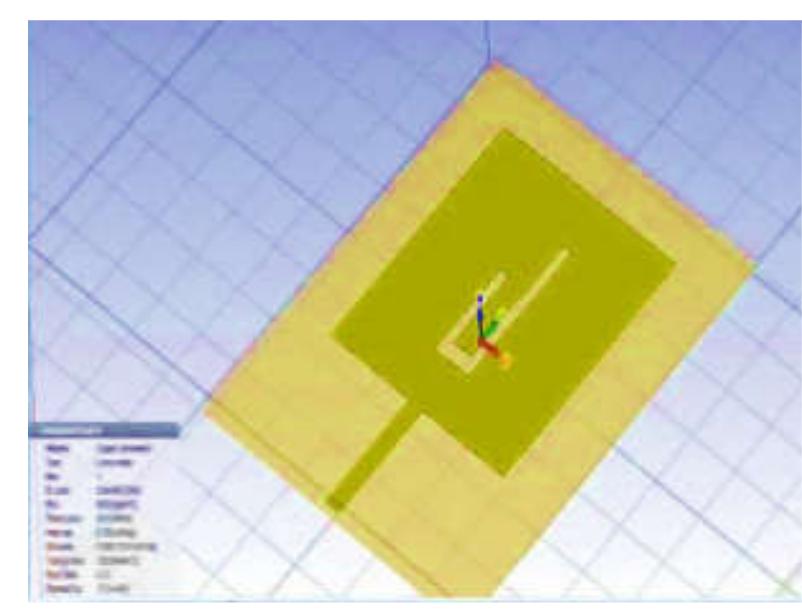

(e)

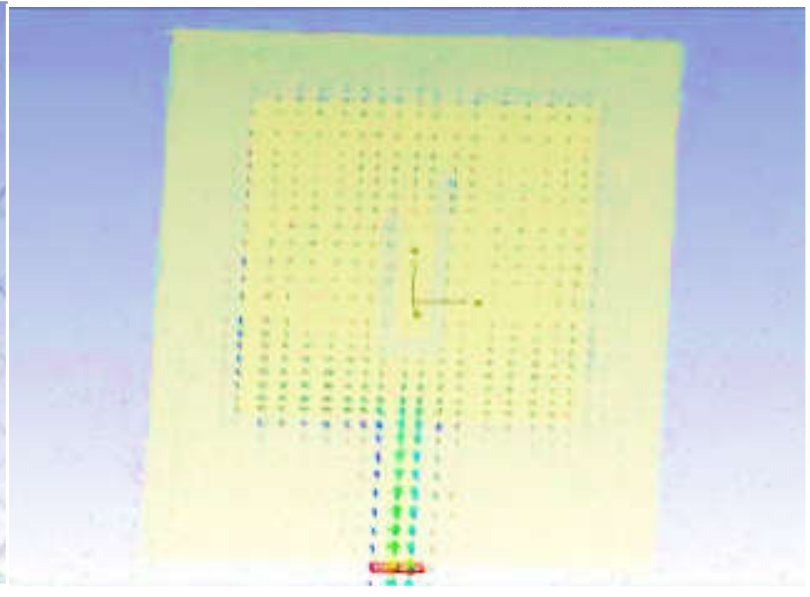

(f)

Fig.3. (a) Ground plane (b) substrate (c) patch antenna, (d) microstrip[18] line (e) the designed antenna, (f) power flow

\section{RESULTS AND DISCUSSION}

The $\mathrm{S}_{11}$ graph shown in Fig. 6 depicts the various resonating frequencies for the proposed antenna with different length of L1. By observing on the graph, it can be concluded that the antenna is resonating at three different frequencies, which are $2.9 \mathrm{GHz}, 3.8 \mathrm{GHz}$ and $4.8 \mathrm{GHz}$.

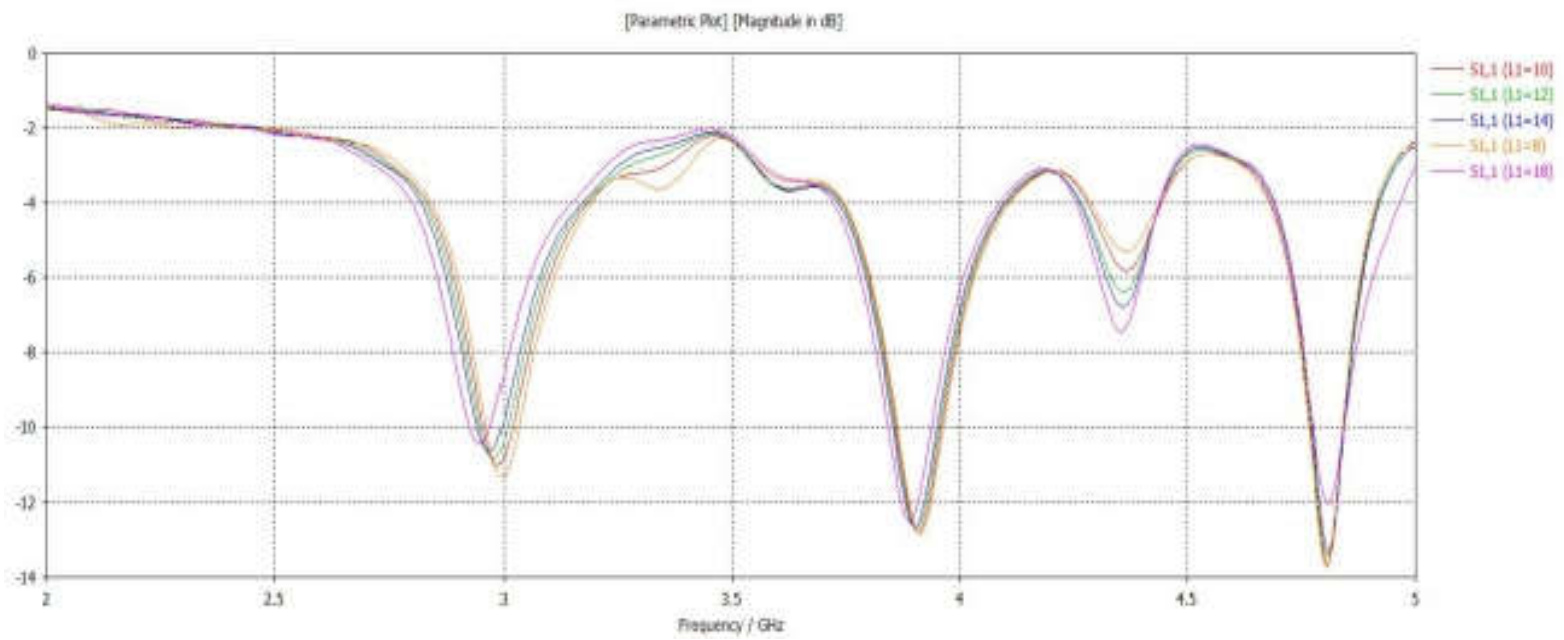

(a) 


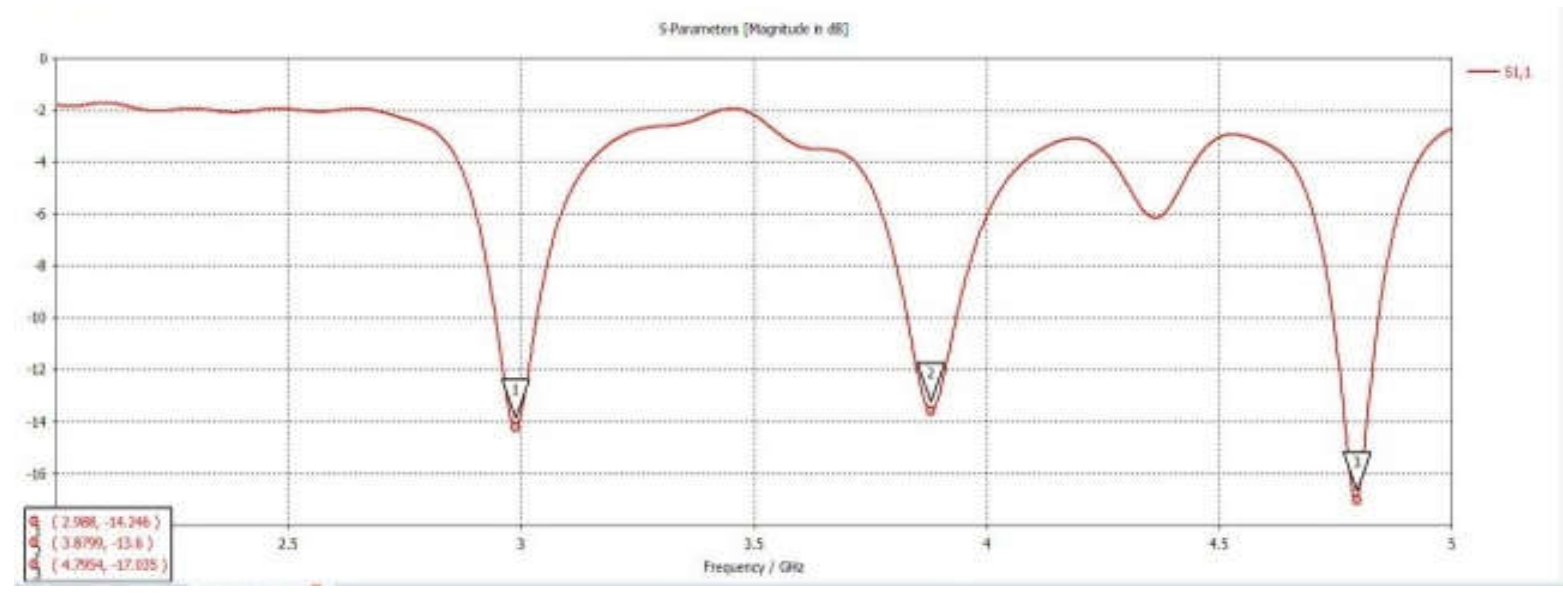

(b)

Fig.4. (a) $\mathrm{S}_{11}$ of the designs (b) $\mathrm{S}_{11}$ of the 4 th designed antenna

The $\mathrm{S}_{11}$ for the three different frequencies is increased as the L1 length increases, but start decreasing at L1 maximum equals to $18 \mathrm{~mm}$. The L1 length was manipulated, so that the return loss obtained is better. The 4 th design of the antenna has the best $\mathrm{S}_{11}$ compared to others. Table 4 shows comparison between five designed patch antennas. The gain for the three frequencies is increasing as the L1 length increases, but stop at maximum value of 18 $\mathrm{mm}$ of L1. It can be concluded that the optimum length for the L1 length are $18 \mathrm{~mm}$.

Table 4. $\mathrm{S}_{11}$ values obtained for five different designed antennas

\begin{tabular}{cccc}
\hline L1 Length $(\mathbf{m m})$ & $\mathbf{S}_{\mathbf{1 1}}$ at $\mathbf{2 . 9} \mathbf{~ G H z}(-\mathbf{d B})$ & $\mathbf{S}_{\mathbf{1 1}}$ at $\mathbf{3 . 8} \mathbf{~ G H z}(-\mathbf{d B})$ & $\mathbf{S}_{\mathbf{1 1}}$ at $\mathbf{4 . 8} \mathbf{~ G H z}(-\mathbf{d B})$ \\
\hline 12 & 10.26 & 12.8 & 12.03 \\
14 & 10.43 & 12.74 & 13.82 \\
16 & 11.32 & 12.95 & 14.06 \\
18 & 14.25 & 13.60 & 17.04 \\
20 & 12.06 & 13.12 & 14.06 \\
\hline
\end{tabular}

In this design, the maximum bandwidth is approximately $30.4 \mathrm{MHz}$ and minimum bandwidth is $21 \mathrm{MHz}$ as tabulated in Table 5. The return loss of the antenna is below $-10 \mathrm{~dB}$. Larger return loss indicates higher power being radiated by the antenna which eventually increases the gain. 
Table5. Parameters at the three operating bands

\begin{tabular}{ccc}
\hline Frequency $(\mathbf{G H z})$ & Bandwidth (MHz) & Efficiency (\%) \\
\hline 2.9 & 30.38 & 74 \\
3.8 & 28.38 & 62 \\
4.8 & 20.58 & 59 \\
\hline
\end{tabular}

The radiation pattern of microstrip[23] patch antenna is the power radiated or received by the antenna. The simulated 3-D radiation pattern in E-plane for the proposed microstrip[24] patch antenna is shown in Fig. 7.

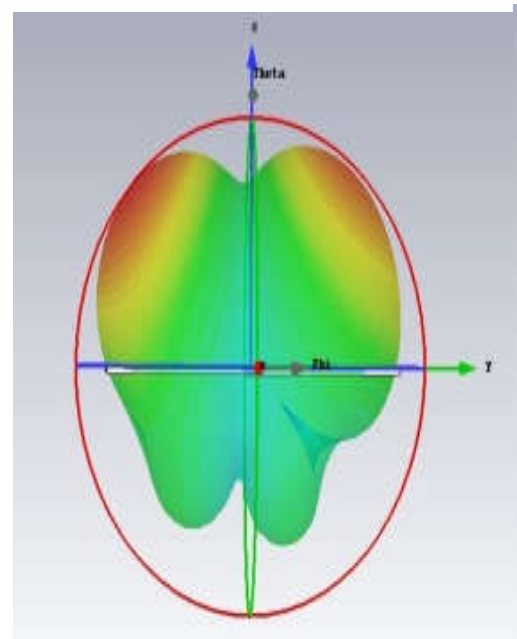

(a)

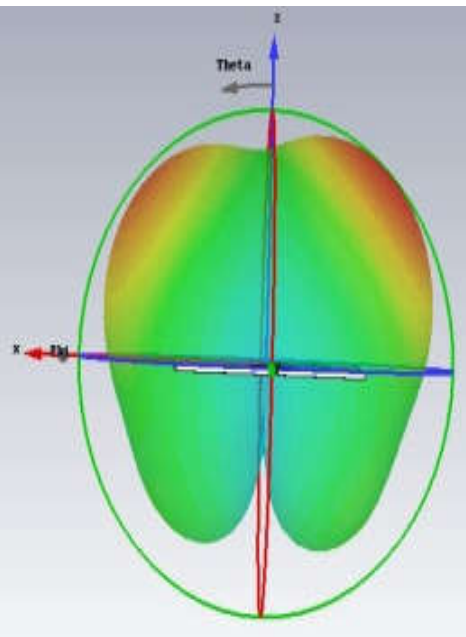

(b)

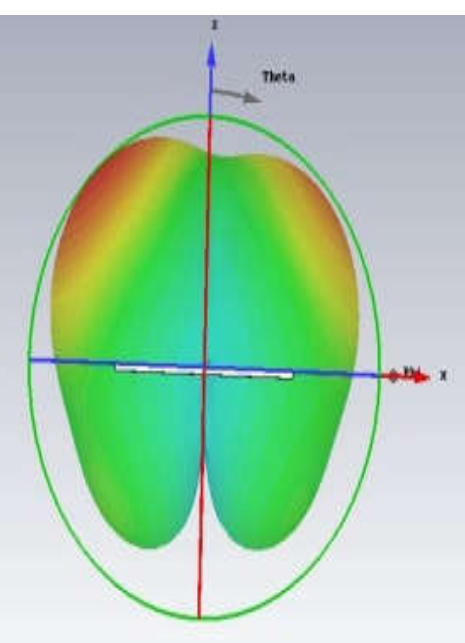

(c)

Fig.5.Simulated 3-D radiation pattern of the antenna, (a) $2.9 \mathrm{GHz}$ E-plane (b) $3.8 \mathrm{GHz}$

$$
\text { E-plane (c) } 4.8 \mathrm{GHz} \text { E-plane }
$$

Fig. 8 shows the simulated far field radiation pattern in E-Plane for frequencies of $2.9 \mathrm{GHz}$, $3.8 \mathrm{GHz}$ and $4.8 \mathrm{GHz}$ respectively. The gain of the antenna is the quantity which describes the performance of the antenna. This is expressed in dB.In a simple way, it can be said that this refers to the direction of the maximum radiation. In this research, the gains are about $1.34 \mathrm{~dB}$ at frequency $2.9 \mathrm{GHz}, 1.22 \mathrm{~dB}$ at $3.8 \mathrm{GHz}$ and $0.98 \mathrm{~dB}$ at $4.8 \mathrm{GHz}$ as shown in Table 6. It can be seen that the antenna can provide stable gains in the three working frequency bands. 
Table 6. Gain at five different designed antenna

\begin{tabular}{cccc}
\hline $\mathbf{L 1}(\mathbf{m m})$ & Gain at $2.9 \mathbf{G H z}(\mathbf{d B})$ & Gain at 3.8 GHz (dB) & Gain at $4.8 \mathbf{G H z}(\mathbf{d B})$ \\
\hline 12 & 0.55 & -0.04 & -0.21 \\
14 & 0.98 & -0.04 & -0.18 \\
16 & 1.21 & 1.17 & 0.67 \\
18 & 1.36 & 1.23 & 0.98 \\
20 & 1.11 & 1.10 & 0.33 \\
\hline
\end{tabular}

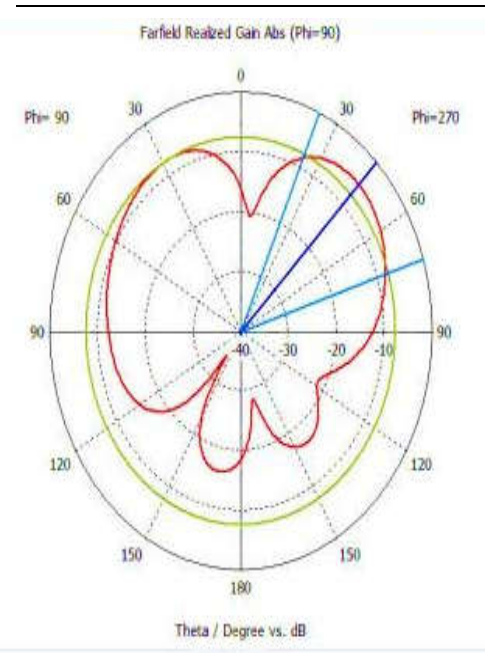

(a)

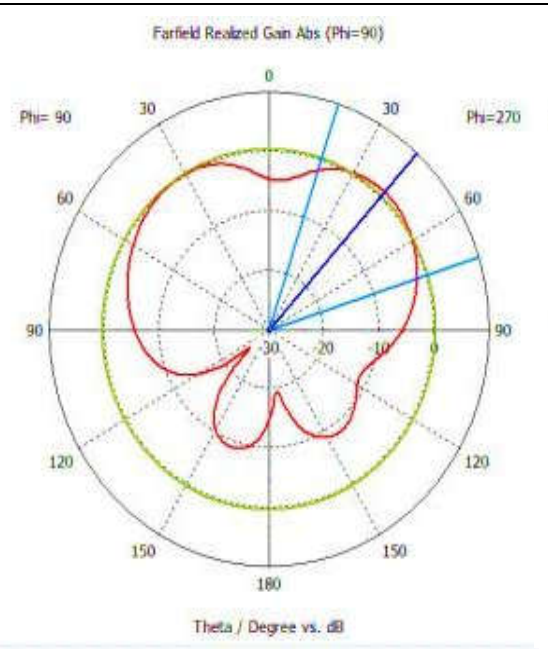

(b)

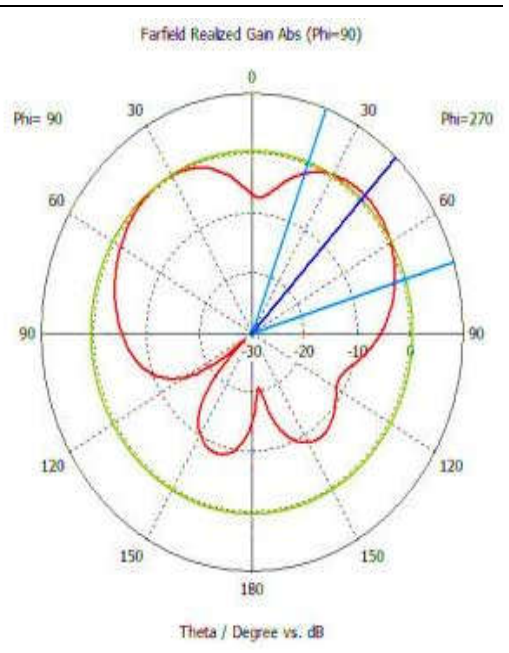

(c)

Fig.8. Simulated radiation patterns in the E-plane. (a) $2.9 \mathrm{GHz}$ (b) $3.8 \mathrm{GHz}$ and (c) $4.8 \mathrm{GHz}$

\section{CONCLUSION}

The designed antenna is able to operate at three difference frequencies which are $2.9 \mathrm{GHz}, 3.8$ $\mathrm{GHz}$ (WiMAX bands) and $4.8 \mathrm{GHz}$ (Wireless LAN bands). The maximum bandwidth in this designed antenna is approximately $40 \mathrm{MHz}$ at 4 th design and gain $1.23 \mathrm{~dB}$. Hence, it is proven that the antenna is able to operate in desired conditions. Despite using two antennas, only one antenna is sufficient to resonate at multiband frequencies. This designed antenna can be used for WiMAX bands and Wireless LAN bands. For further study, there are some recommendations to improve the performance of the antenna. Firstly, to enhance the bandwidth, some parametric variation can be done such as change in substrate type and its thickness. The designed antenna is quite large for mobile communication.For future suggestion, the size of antenna should be reduced. 


\section{ACKNOWLEDGEMENTS}

The author would like to thank EE Department of Faculty of Engineering, UPNM for providing CST software to be used by final year student for the first time in the university.

\section{REFERENCES}

[1] Committee A, Antennas I, Society P. IEEE standard for definitions of terms for antennas. IEEE Antennas and Propagation Society, 2013, 34(2):31-40

[2] Jegan G, Vimala J, Ashok K G. Multi band microstrip patch antenna for satellite communication.In IEEE Recent Advances in Space Technology Services and Climate Change, 2010, pp. 153-156

[3] Mandal A, Ghosal A, Majumdar A, Ghosh A, Das A, Das S K. Analysis of feeding techniques of rectangular microstrip antenna. In IEEE International Conference on Signal Processing, Communication and Computing, 2012, pp. 26-31

[4] Huynh T, Lee K F. Single-layer single-patch wideband microstrip antenna. Electronics Letters, 31(16):1310-1312

[5] Dwivedi S, Rawat A, Yadav R N. Design of U-shape microstrip patch antenna for WiMAX applications at $2.5 \mathrm{GHz}$. In 10th IEEE International Conference on Wireless and Optical Communications Networks, 2013, pp. 1-5

[6] Lee K F, Tong K F. Microstrip patch antennas-Basic characteristics and some recent advances. Proceedings of the IEEE, 2012, 100(7):2169-2180

[7] Lee KF, Yang SL S, Kishk AA. Dual- and multiband U-slot patch antennas. IEEE Antennas and Wireless Propagation Letters, 2008, 7:645-647

[18] Azahar F, Zairi I R.Design and fabrication of $12 \mathrm{GHz}$ microstrip directional coupler for RF/microwave application.Journal of Engineering Science and Technology, 2016, 11(3):431-442

[19] Mohd A A, Ermeey A. K, Mohamad Y M Z, Zairi I R, Nur H R H. A miniature UHF rectangular microstrip RFID tag antenna for aluminium can application.World Applied Sciences Journal, 2013, 23(23):96-102

[20] Nik N S N D, Zairi I R, Nur H R H. Double layer microstrip antenna with 3 by 3 array of square parasitic patches using coaxial feeding technique for WiMAX application.Journal of Basic and Applied Scientific Research, 2013, 3(11):399-404 
[21] Suziana O, Zairi I R, Nur H R H. Gain enhancement of rectangular microstrip patch antenna using t-probe fed for mobile and radio wireless communication applications.Journal of Basic and Applied Scientific Research, 2013, 3(10):456-464

[22] Rosmawati S, Zairi I R, Suziyani R, Nur H R H. Enhancement of microstrip circular patch antenna performances using DGS technique for wireless communication application.Journal of Basic and Applied Scientific Research, 2013, 3(11):365-372

[23] Nik N S N D, Mohd T A, Zairi I R, Suziana O, Rina A, Nuraiza I, Nur H R H.3x3 array of square parasitic patches double layer microstrip antenna design.In National Seminar onApplicationof ScienceandMathematics, 2013, pp. 71-77

[24] Suziana O, Mohd T A, Zairi I R, Nuraiza I, Rosmawati S, Nur H R H. A rectangular microstrip patch antenna design using t-probe feed for WIMAX application.In National Seminar onApplicationof ScienceandMathematics, 2013, pp. 79-86

\section{How to cite this article:}

Husin M N, Jusoh M T, Din M F M. Study and design of u-shaped patch antenna for multiband applications. J. Fundam. Appl. Sci., 2017, 9(3S), 578-589 